\title{
Why do we need to empower university staffs and students for tackling the non-communicable diseases?
}

\author{
Supriyati, ${ }^{1,2, *}$ Anggi Lukman Wicaksana, ${ }^{3}$ Esthy Sundari, ${ }^{1}$ Heny Suseani Pangatuti, ${ }^{3}$ and Fatwa Sari \\ Tetra Dewi ${ }^{1,2}$
}

'Department of Health Behavior, Environment, and Social Medicine, Faculty of Medicine, Public Health and Nursing, Universitas Gadjah Mada, Yogyakarta, Indonesia

${ }^{2}$ Center of Health Behavior and Promotion, Faculty of Medicine, Public Health and Nursing, Universitas Gadjah Mada, Yogyakarta, Indonesia

${ }^{3}$ Department of Medical Surgical Nursing, Faculty of Medicine, Public Health and Nursing, Universitas Gadjah Mada,

Yogyakarta, Indonesia

\section{KEYWORDS}

Health promoting university

Non-communicable disease

\begin{abstract}
Non-communicable diseases (NCDs) are a major cause of death in Indonesia and worldwide. Yogyakarta has the highest prevalence of cancer in Indonesia. Besides, Yogyakarta has high prevalence of diabetes mellitus and other NCDs. The prevention and control of NCDs are direly needed in Yogyakarta. Universitas Gadjah Mada (UGM) is the oldest university in Yogyakarta and has a large number of university staff members and students. This study aimed to empower university staff and students of UGM in the health promotion programs for tackling NCD risk factors through the Health Promoting University initiative. This was a participatory action research that was conducted in UGM, Yogyakarta. A total of 299 respondents (university staff and students in second year) were involved in the need's assessment survey. Data were collected through online questionnaire and analyzed descriptively. Additionally, advocacy, training, small group discussion, seminars, discussion on WhatsApp group, as well as developing posters for healthy diet, hand washing, physical activities, and smoking behavior were done as the follow-up of the need's assessment. The need's assessment showed that most respondents had a poor knowledge on the NCDs and its risk factors $(74 \%)$, poor knowledge on the smoke free campus ( $80 \%)$, had insufficient vegetables consumption (83\%), had insufficient fruit consumption (68\%), and had physically inactive behavior $(52 \%)$. Furthermore, group discussions with the students improved their awareness on the NCD problems among students. Also, training for the university staff members improved their knowledge and skills related to the NCD risk factors' measurement. The university staff and students' knowledge and practice concerning the NCD risk factors prevention were poor. Therefore, the Health Promoting University initiative is a good way to empower them about the NCD risk factors prevention.
\end{abstract}

(c) The Journal 2021. This article is distributed under a Creative Commons Attribution-ShareAlike 4.0 International license.

\section{Introduction}

Non-communicable diseases (NCDs) are one of the major causes of death in the world, ${ }^{1}$ including in Indonesia. Yogyakarta is facing many problems related to NCDs, such as having the highest prevalence of cancer in Indonesia, a high prevalence of diabetes mellitus and a low level of physical activity with low level of fruit and vegetable consumption. ${ }^{2,3}$ On the other hand, the ASEAN University Network -

*Correspondence: supriyati@ugm.ac.id

Department of Health Behavior, Environment, and Social Medicine, Faculty of Medicine, Public Health, and Nursing, Universitas Gadjah Mada, JI. Farmako, Sekip Utara, Yogyakarta 55281, Indonesia
Health Promoting Network (AUN-HPN) encourages universities in the ASEAN region to be active in controlling and preventing NCDs by implementing the Health Promoting University (HPU) programs. ${ }^{4}$ Universitas Gadjah Mada (UGM) is one of the universities in Indonesia that actively contributes to develop the AUN-HPN framework for a healthy campus. $^{5}$

There are 13 thematic areas of HPU, including: zero tolerance of alcohol and drug abuse, zero tolerance of tobacco use, health promotion for physical activities and health promotion for healthy diet. Those are the four major risk factors of the NCDs. ${ }^{1}$ In addition, the target of the HPU programs 
is not limited to the university's members, but also targeted to the community around the university. ${ }^{4}$ Lecturers, students, and other university staff play an important role as the 'agents of change' for the community. ${ }^{6}$ This means that the implementation of HPU in the university will contribute to solve the NCD problems in Yogyakarta communities.

The burden of NCDs is progressively increasing. Various health promotion strategies need to be implemented to overcome the burden, i.e., advocacy, creating supportive environment, capacity building, and community empowerment. Community empowerment is one of the important strategies for tackling the NCD problems. ${ }^{7}$ Besides these efforts, health promotion programs need to engage various stakeholders to increase the effectiveness of the programs. ${ }^{8}$ University staff and students are potential stakeholders for the health promotion programs within university settings. This study aimed to empower university staff and students for tackling NCD problems in the UGM Yogyakarta.

\section{Method}

This was a participatory action research (PAR) that was conducted in the Universitas Gadjah Mada (UGM), Yogyakarta. There are five steps of PAR: (1) engage with real world setting/situation, (2) defining the issue by using initial observation or existing data, (3) planning an action/ intervention, (4) taking action/ intervention, and (5) analyzing and reflecting on the action/intervention conducted in the PAR study. The PAR approach was chosen to improve the participants' engagement in the program. ${ }^{9,10}$ Online surveys were performed to engage with the real world setting. Respondents were university staff members and students of UGM who were voluntarily recruited through the online survey. A total of 299 respondents (157 students, 127 university staff, and 15 lecturers) agreed to participate in this study. The students involved in this study were second year students of undergraduate and vocational study programs. Furthermore, the problem priority (issue) was defined according to the survey results.

An action plan was developed by the research team in collaboration with the potential stakeholders to empower university staff members and students for tackling NCD risk factors through the Health Promoting University initiative. The action plan was designed through intensive discussions among the research team and the potential stakeholders, i.e., students, university staff, the coordinator of the safety, and the Health and Environment unit of the Faculty of Engineering UGM. Developing networks, advocacy, group discussions, creating health promotion media, conducting seminar on the healthy life style, and capacity building were done as the intervention steps. The intervention was conducted in collaboration with many stakeholders in UGM including, faculty stakeholders in the Faculty of Medicine, Public Health and Nursing, faculty stakeholders in the Engineering Faculty, Human Resources unit of UGM, and the coordinator of the Safety, Health, and Environment unit of UGM. Furthermore, formative evaluation was done through
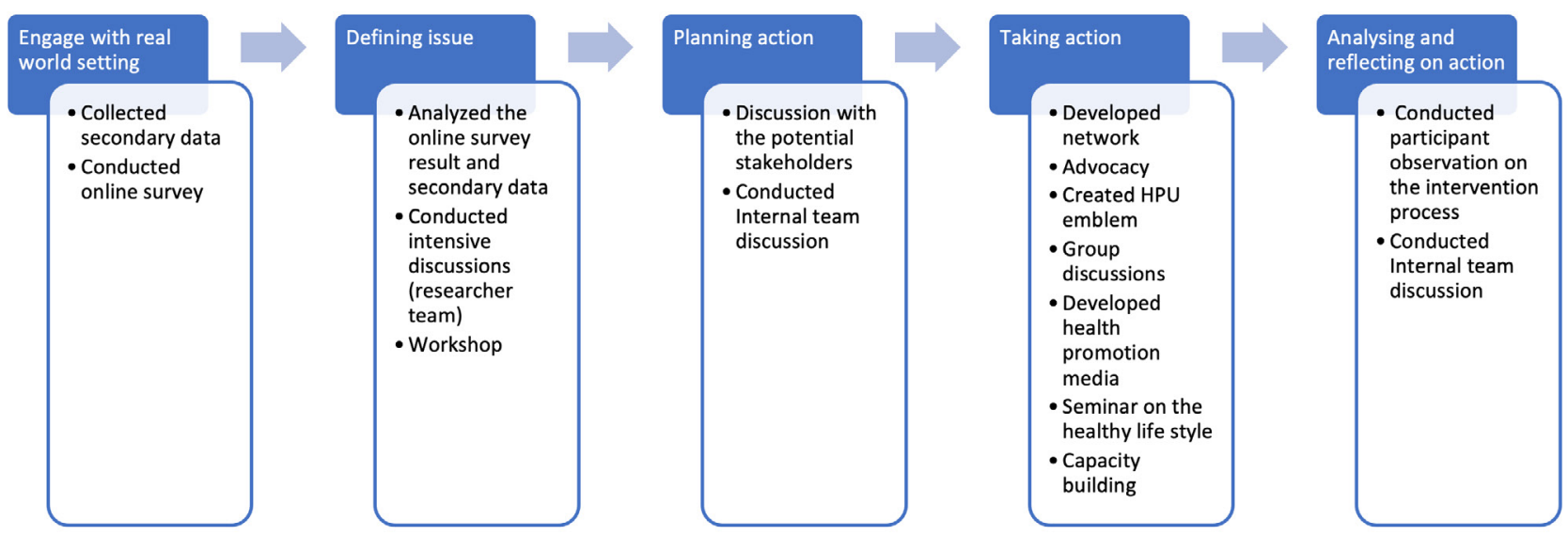

Figure 1. The study stages 
Table 1. Need's assessment results

\begin{tabular}{|c|c|}
\hline Variables & n (\%) \\
\hline \multicolumn{2}{|l|}{ Status } \\
\hline Lecturer & $15(5)$ \\
\hline University staff & $127(42)$ \\
\hline \multirow[t]{2}{*}{ Student } & $157(53)$ \\
\hline & $299(100)$ \\
\hline \multicolumn{2}{|l|}{ Sex } \\
\hline Male & $99(33)$ \\
\hline \multirow{2}{*}{ Female } & $200(67)$ \\
\hline & $299(100)$ \\
\hline \multicolumn{2}{|c|}{ Knowledge on the NCD and its risk factors } \\
\hline Poor & $221(74)$ \\
\hline \multirow[t]{2}{*}{ Good } & $78(26)$ \\
\hline & $299(100)$ \\
\hline \multicolumn{2}{|c|}{ Knowledge on the smoke free campus } \\
\hline Poor & $239(80)$ \\
\hline \multirow[t]{2}{*}{ Good } & $60(20)$ \\
\hline & $299(100)$ \\
\hline \multicolumn{2}{|l|}{ Vegetables consumption } \\
\hline$<3$ portion / day & $248(83)$ \\
\hline \multirow[t]{2}{*}{3 portion and up / day } & $51(17)$ \\
\hline & $299(100)$ \\
\hline \multicolumn{2}{|l|}{ Fruits consumption } \\
\hline$<2$ portion / day & $203(68)$ \\
\hline \multirow[t]{2}{*}{2 portion and up / day } & $96(32)$ \\
\hline & $299(100)$ \\
\hline \multicolumn{2}{|l|}{ Physical activities } \\
\hline$<150$ minutes / week & $155(52)$ \\
\hline \multirow[t]{2}{*}{150 minutes and up / week } & $144(48)$ \\
\hline & $299(100)$ \\
\hline
\end{tabular}

observations within the intervention process. Finally, internal reflection was performed to analyze and evaluate the intervention. Figure 1 describes the stages of this study.

This study was conducted in April - November 2018. Furthermore, this study was approved by the Medical and Health Research Ethics Committee of the Faculty of Medicine, Public Health and Nursing UGM (no. Ref.: KE/FK/073/EC/2018).

\section{Result}

The results are presented according to the participatory action research steps, which were performed in this study.

\subsection{Engage with real world setting/situation}

The process to engage with real world setting which was the UGM situation related to the NCDs was done through secondary data and primary data collections. The secondary data showed that $58 \%$ out of 611 fresh graduates were facing some health problem according to the ECC survey in 2014. Furthermore, the online survey to assess university staff and students' need for the health intervention showed that they had poor knowledge and practice related to the NCD prevention (Table 1).

There are 18 faculties for the undergraduate programs and one faculty for the vocational program in UGM. Respondents came from all faculties in UGM. Table 1 shows that most of respondents (53\%) were students. Basically, this survey was targeted to students and university staff members. Fortunately, there were 15 out of 299 respondents (5\%) lecturers involved in this survey. They completed the online survey because they were interested in the health intervention. Surprisingly, they came from various faculties in UGM, and were not limited to the health science faculty. Most respondents (67\%) were female.

Generally, university staff and students had poor knowledge on the NCDs and its risk factors (74\%), and poor knowledge on the smoke free campus (80\%). Moreover, they had inadequate vegetables $(83 \%)$ and fruits $(68 \%)$ consumption, as well as were physically inactive (52\%).

\subsection{Defining the issue}

Internal discussions and workshops (researcher team) were done to define the issue. According to the needs assessment results and discussion, this study was focused on the healthy life style intervention. Therefore, this study was initiated to implement the Health Promoting University (HPU) framework.

\subsection{Designing program planning}

There were several program steps initiated in this study, such as advocacy, developing health promotion media, seminar, capacity building, as well as created supportive environment. Advocacy had been conducted to get policy support from the Faculty of Medicine, Public Health and Nursing; Faculty of Engineering, Vice Rector for human resources and assets UGM, Center for Safety, Occupational Health and Environment UGM, as well as UGM Medical 


\section{Center.}

Health promotion media are important to increase university staff and students' knowledge on the NCDs risk factors. Health promotion media and seminar material were designed to improve their knowledge and awareness on the importance of NCD prevention. This study also recruited university staff members to become HPU cadres. Furthermore, training was designed to increase the HPU cadres' knowledge and skills for developing Posbindu (healthy post) programs. Besides, group discussions also planned to increase student knowledge and awareness regarding NCD prevention.

This designing program step was performed by engaging university staff and students. It was conducted to increase their sense of belonging toward the program and develop good networking.

\subsection{Taking action}

As the result of the program planning step, there were various activities conducted in this phase. First, advocacy was done with the policymakers in the Faculty of Medicine, Public Health and Nursing; and the Faculty of Engineering UGM. They agreed with the HPU initiative program and stated that will support the program.

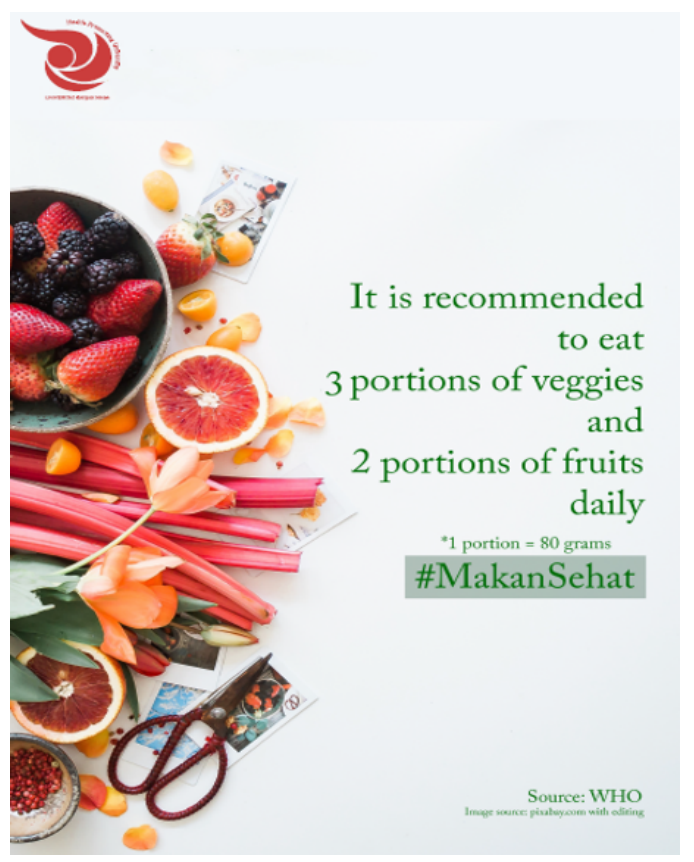

(a)
The Health Promoting University UGM emblem was then created by modifying the health promotion emblem for familiarizing the HPU initiative. These emblems were used for any kind of health promotion medias and all posters of the HPU activities. Health promotion medias were developed with several messages such as healthy diet, physical activities, alcohol and smoking prevention and control, as well as hand washing (Figure 2).

The process to increase university staff and students' knowledge and awareness on the NCD risk factors was done through developing health promotion medias, group discussions, and a half-day seminar on the healthy life style for healthy staff and students. The university staff and students were very enthusiastic to participate in the seminar, in which the Declaration of a Health Promoting University was done. All seminar participants were allowed to sign and express their support to the HPU initiative in UGM.

The half-day seminar was supported by the UGM vice rector for Resources and Assets Affair as well as the dean and vice deans of the Faculty of Medicine, Public Health and Nursing UGM. The seminar participants were 215 people. Most of them were students, followed by the university staff

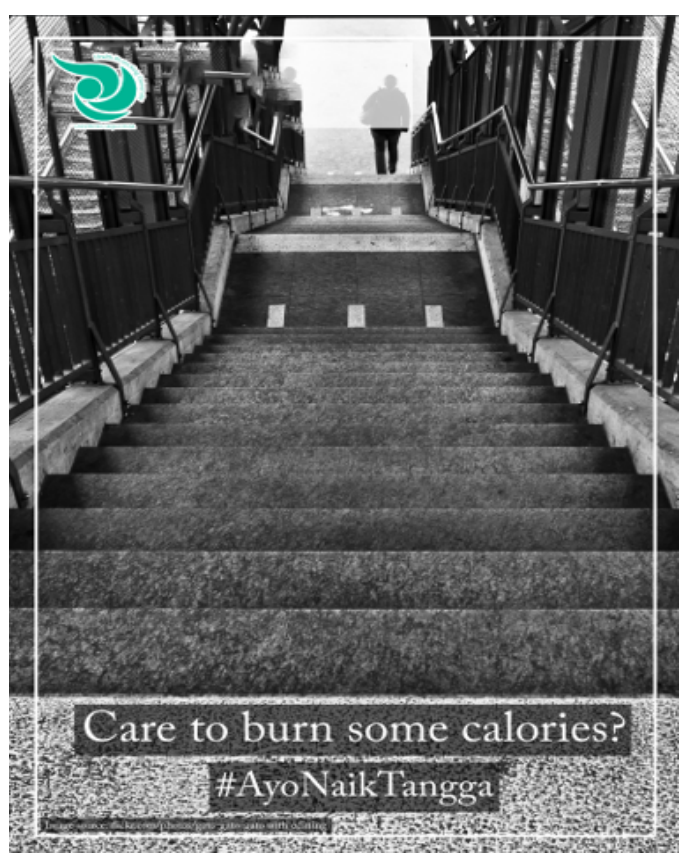

(b)

Figure 2. Posters as the health promotion media: (a) Healthy diet message; and (b) Physical activity message 


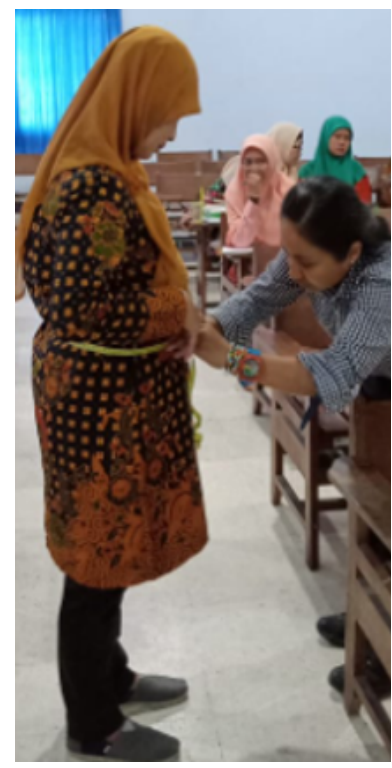

(a)

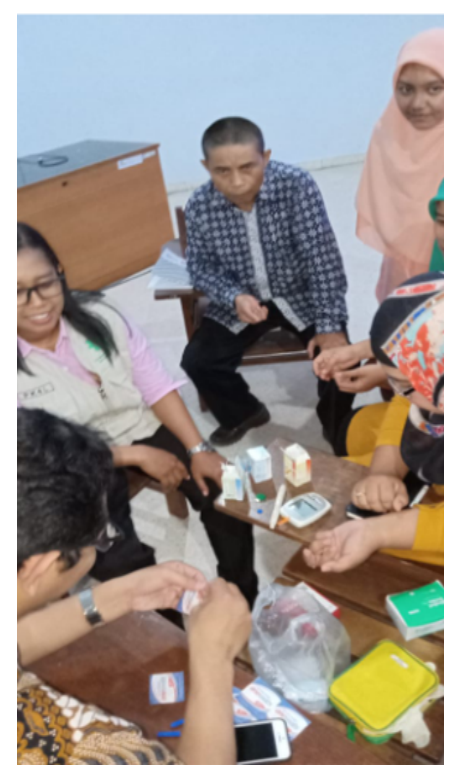

(b)

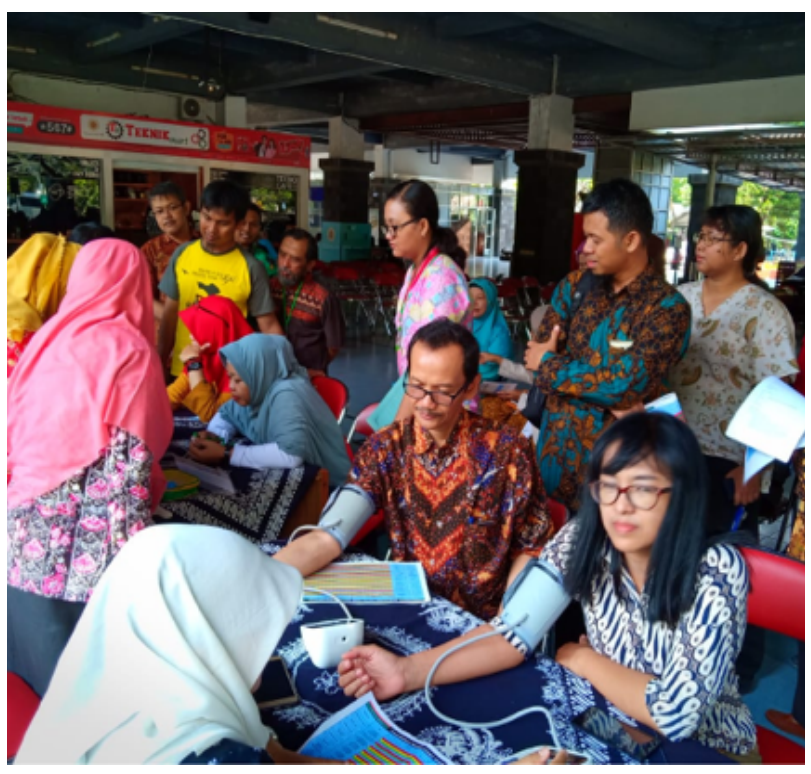

(c)

Figure 3. Training for HPU Cadres \& Launching Posbindu PHSS; (a) roleplay on the waist measurement; (b) role play for the cholesterol and blood glucose check; and (c) Posbindu PHSS

members and lecturers. In addition, the responses of the university staff and students were beyond the expectation. The seminar committee had to refuse several seminar participants due to the auditorium capacity. Many questions and suggestions came from the seminar participants for the HPU program. This response reflected that the half-day seminar could succeed to raise people's awareness of the NCD problems among university staff members and students. Moreover, many local newspapers published the news of the seminar.

The next step of the implementation program of the HPU program was to develop the Posbindu Promosi Hidup Sehat dan Sejahtera- Posbindu PHSS (healthy post - Promoting healthy life style and wellness) in the Faculty of Engineering. Twenty university staff members of Faculty of Engineering became voluntary HPU cadres. They participated in a two-day training for HPU cadres and then actively prepared the launching of the Posyandu PHSS (Figure 3). Furthermore, an active WhatsApp group for the HPU cadres and research team was created as the communication channel to improve their knowledge and discussion of the many issues related to the NCD and their prevention strategies, especially for improving their self-efficacy to become an HPU cadre. Being HPU cadres excited them since it was very different with their daily activities. This program was also significantly supported by the Faculty of Engineering UGM.

The dean of the Engineering Faculty UGM launched the Posbindu PHSS in October 2018, and more than 60 lecturers and university staff members were involved in this event. The first Posbindu demonstrated that the HPU cadres are able to fulfill their role as health cadres, and they had a good self-efficacy for being health cadres. Indeed, the agenda activities were documented and published by various local newspapers. It was the first Posbindu in the university and even the first in a workplace setting in Yogyakarta. The Posbindu PHSS works in collaboration with the Gadjah Mada Medical Center for the referral system.

Three small group discussions (10 students for each group) with engineering students were conducted to strengthen their knowledge and attitudes toward NCD risk factors prevention and control/treatment. The small group discussions focused on the problems and solutions for the smoking behavior in the university setting, healthy diet, as well as physical inactivity. First, participants tried to identify NCD risk factors in problems in the 
university setting. Afterward, they discussed ways to find the best solutions for the problems. Even though the discussion theme was very different with their education background, they were still eager to follow the discussion instructions. Surprisingly, they expressed their idea about the problems and solutions in a comprehensive mind map.

\subsection{Evaluating and reflecting on the intervention}

This step showed that the HPU initiative met the university staff and students' need. The HPU initiative increased their knowledge and attitudes toward NCD risk factors. Besides, university staff members potentially became HPU cadres even though they did not have an education background from the health sciences and they did not have any other experiences as health cadres. According to the observations that were performed during the intervention process, the group discussions, half-day seminar, health promotion media, and the training improved participants' knowledge and skills related to the NCD risk factors prevention and the measurement. Furthermore, the policy support from the Faculty of Medicine, Public Health, and Nursing as well as Engineering Faculty was a strengthening action in the HPU initiative.

\section{Discussion}

This study indicated there were four factors that contributed to the success of the HPU initiative as a strategy for tackling NCDs in UGM. First, the strategy to approach the target was engaging and empowering. Secondly, the needs assessment made the connection between researchers and the community target, because the data used to develop the program were real coming directly from the community target. Third, there was policymaker support including emotional and instrumental support. The last was the supportive environment and capacity building that had been conducted which made people to easily practice the suggested behaviors. Those strengths of the HPU program improved community ownership of the program activities. The community ownership indicates the sustainability of the HPU program. ${ }^{11}$ Sustainability is a very important issue for the health promotion initiative. $^{12}$

The Ottawa Charter recommended five areas for action of health promotion, i.e., building healthy public policy, creating supportive environment, strengthening community action, developing personal skills as well as reorientation of health services. ${ }^{13}$ The implementation stage of this study was started by conducting advocacy to convince the policymakers at the faculty level to build public health policies and create a more supportive environment to practice healthy life style. Moreover, this study conducted capacity building through training and intensive discussion to develop the target audience's personal skills. According to Wahid ${ }^{(14)}$, capacity building is the key component of the community empowerment. Building capacity at the local level of the stakeholders will increase community ownership and participation. ${ }^{7,14}$ The program approach by using the PAR methods enabled the researchers to find the community's real needs ${ }^{15}$ and engage stakeholders. ${ }^{9,10}$ This contributed to the success of the health promotion programs.

The community-based participatory health literacy program is known to be effective in improving health behavior and empowerment among adults. ${ }^{11}$ This study tried to engage community targets which are university staff members and students through various activities in the HPU initiative. The PAR approach helps health providers to find the community targets' real needs and identify ways to get closer to them. ${ }^{15}$

Advocacy and network development were done in this study to engage stakeholders. Engaging stakeholders increased their participation.7,12,16 Furthermore, the success of the advocacy led to the policymakers' support that enables creating a more supportive environment. ${ }^{17}$ The socioecological model explains that health promotion needs to be done through multiple strategies of health promotion including downstream and upstream strategies. ${ }^{18}$

This study did not conduct post-tests after all the intervention steps had been performed. Moreover, this article did not provide a statistical data analysis of the impact of the intervention. These are some of the limitations of this study.

This study suggests to the health promotion 
experts to engage and empower research subjects for increasing the community participation. Moreover, community participation will lead to a more successful health promotion in the university setting.

\section{Conclusion}

The Health Promoting University initiative that had been done by involving university staff and students could improve their awareness and skills concerning the NCDs prevention. Furthermore, university staff members and students became potential 'agents of change' for better health in the community. Thus, health providers need to engage university staff and students for tackling NCD risk factors or promoting other health programs.

\section{Acknowledgements}

This study was partially supported by community services grant UGM scheme education for sustainable development in 2018. We express our gratitude to the Faculty of Medicine, Public Health and Nursing as well as Faculty of Engineering UGM for their support and kind cooperation for this study.

\section{Conflict of interests}

There no conflict of interest in this study.

\section{References}

1. Collaborators NC. NCD Countdown 2030: pathways to achieving Sustainable Development Goal target 3.4. The Lancet. 2020;396(10255):918-34.

2. Fles R, Bos A, Supriyati, Rachmawati D, Waliyanti E, Tan IB, et al. The role of Indonesian patients' health behaviors in delaying the diagnosis of nasopharyngeal carcinoma. BMC Public Health. 2017;17(1):510.

3. Waliyanti E, Dewi FST, Supriyati S, Fles R. Treatment-seeking behaviour of nasopharyngeal cancer patients in Yogyakarta, Indonesia. Pan Afr Med J. 2018;29:98-.

4. Network AUNHP. AUN Healthy University Framework. 2nd edition ed. Thailand; 2017.
5. AUN-HPN. AUN Healthy University Framework. 2 ed. Thailand; 2017.

6. Wakkee I, van der Sijde P, Vaupell C, Ghuman K. The university's role in sustainable development: activating entrepreneurial scholars as agents of change. Technological Forecasting and Social Change. 2019;141:195-205.

7. Dewi FST. Working with community : exploring community empowerment to support noncommunicable disease prevention in a middleincome country [Doctoral thesis, comprehensive summary]. Umeå: Umeå universitet; 2013.

8. Suárez-Reyes $M$, Broucke SVd. Implementing the Health Promoting University approach in culturally different contexts: a systematic review. Global Health Promotion 2016; Vol 23 Supp. 1:46-56.

9. Kim $H$, Shon $S$, Shin $H$. Exploring the unmet needs for creating an enabling environment for nurturing care to promote migrant child health in Bishkek, Kyrgyzstan: a theory-guided communitybased participatory action research. Evaluation and Program Planning. 2020;80:101802.

10. Baum FE. Power and glory: applying participatory action research in public health. Gaceta Sanitaria. 2016;30(6):405-7.

11. Lin S-C, Chen IJ, Yu W-R, Lee S-YD, Tsai T-I. Effect of a community-based participatory health literacy program on health behaviors and health empowerment among community-dwelling older adults: a quasi-experimental study. Geriatric Nursing. 2019;40(5):494-501.

12. Laverack G. Health Promotion Practice : Building Empowered Communities: McGraw-Hill Education, UK; 2007.

13. Madsen W. History in health: health promotion's underexplored tool for change. Public Health. 2018;154:118-22.

14. Wahid A, Ahmad MS, Abu Talib NB, Shah IA, Tahir M, Jan FA, et al. Barriers to empowerment: Assessment of community-led local development organizations in Pakistan. Renewable and Sustainable Energy Reviews. 2017;74:1361-70.

15. Bisung $E$, Dickin S. Concept mapping: engaging stakeholders to identify factors that contribute to empowerment in the water and sanitation sector in West Africa. SSM - Population Health. 
2019;9:100490.

16. Hoon Chuah FL, Srivastava A, Singh SR, Haldane V, Huat Koh GC, Seng CK, et al. Community participation in general health initiatives in high and upper-middle income countries: a systematic review exploring the nature of participation, use of theories, contextual drivers and power relations in community participation. Social Science \& Medicine. 2018;213:106-22.

17. Sawyer A, Ucci M, Jones R, Smith L, Fisher A. Supportive environments for physical activity in deprived communities in the United Kingdom: a qualitative study using photo elicitation. Social Science \& Medicine. 2018;197:49-58.

18. Snelling AM. Introduction to Health Promotion. John Willey \& Son: USA; 2014. 